\title{
Declining trends in smokeless tobacco use among Indian women: findings from global adult tobacco survey I and II
}

\author{
Shishirendu Ghosal ${ }^{\dagger}$, Abhinav Sinha ${ }^{\dagger}$, Srikanta Kanungo ${ }^{*}$ and Sanghamitra Pati
}

\begin{abstract}
Background: Smokeless Tobacco (SLT) use is culturally rooted and more acceptable among women in India. SLT is a significant risk for oral cancers and has other adverse health outcomes on women's general as well as reproductive health. This study aimed to estimate and compare the prevalence and correlates of SLT among adult females in India using Global Adult Tobacco Survey (GATS), 2009-2010 (GATS 1) and 2016-2017 (GATS 2).

Methods: Data from a nationally representative cross-sectional study GATS $1(n=35,529)$ and GATS $2(n=40,265)$ were analysed for adult female smokeless tobacco users. Correlates of SLT exposure were assessed separately using binary logistic regression. Multivariable logistic regression analysis was done for the variables which computed $p<0.1$. The association was expressed as Adjusted Odds ratio with 95\% confidence intervals.

Results: There was a reduction in prevalence of SLT use among women in India between GATS 1 (18.4\%) and GATS 2 (12.8\%). SLT use was highest among the North-Eastern women in both rounds [AOR: 4.567 (3.942-5.292) during GATS-1 and 9.149 (7.722-10.839) during GATS-2]. Odisha had highest prevalence of 56.53\% while Himachal Pradesh had lowest $0.14 \%$ during the recent GATS 2 survey. $33.3 \%$ vs. $34.80 \%$ of the participants were willing to quit tobacco in Central region across both rounds of survey.

Conclusions: Although, smokeless tobacco prevalence among females has reduced between 2009 and 2016 in India, yet tobacco control strategies need further pace. Hence, more focused gender-based tobacco control programs and policies are the need of time.
\end{abstract}

Keywords: GATS, India, Oral Cancer prevention, Smokeless tobacco, Women

\section{Background}

Smokeless tobacco (SLT) refers to the products which are consumed without combustion through chewing, spitting, dipping, snuffing and applying on teeth and gums [1, 2]. There are 248 million SLT users globally, $90 \%$ of whom live in Indian subcontinent [3]. Tobacco consumption is more widespread amongst males but, it is evident that young girls and women tend to use SLT

\footnotetext{
*Correspondence: srikantak109@gmail.com; drsanghamitra12@gmail.com †Shishirendu Ghosal and Abhinav Sinha contributed equally to this work. Division of Public Health, ICMR-Regional Medical Research Centre,

Chandrasekharpur, Bhubaneswar, Odisha -751023, India
}

more as compared to smoking [4]. Behavioral science attributes socio-cultural practices and acceptability of SLT as one of the reasons for extensive SLT use amongst females $[5,6]$.

SLT is a potential threat for women's general as well as reproductive health [7]. Regular SLT consumption leads to several adverse health outcomes such as oropharyngeal cancers, heart diseases, osteoporosis, reproductive morbidities including infertility and pregnancy complications $[8,9]$. Its use during pregnancy can lead to pre-term delivery, low birth weight babies, stillbirth and may act as neuro-teratogen affecting development

(c) The Author(s). 2021 Open Access This article is licensed under a Creative Commons Attribution 4.0 International License, which permits use, sharing, adaptation, distribution and reproduction in any medium or format, as long as you give appropriate credit to the original author(s) and the source, provide a link to the Creative Commons licence, and indicate if changes were made. The images or other third party material in this article are included in the article's Creative Commons licence, unless indicated otherwise in a credit line to the material. If material is not included in the article's Creative Commons licence and your intended use is not permitted by statutory regulation or exceeds the permitted use, you will need to obtain permission directly from the copyright holder. To view a copy of this licence, visit http://creativecommons.org/licenses/by/4.0/. The Creative Commons Public Domain Dedication waiver (http://creativecommons.org/publicdomain/zero/1.0/) applies to the data made available in this article, unless otherwise stated in a credit line to the data. 
of nervous system in the fetus [10, 11]. In general, SLT use has also been associated with compromised nutritional status leading to weak immunity and increased vulnerability to infections $[12,13]$.

SLT is one of the leading cause of potentially malignant oral soft tissue lesions such as leukoplakia, erythroplakia and oral submucous fibrosis; eventually leading to oral cancers [14]. Various studies suggest a strong causal relation between SLT use and oral cancer [15]. Oral cancer is one of the top three cancers accounting $30 \%$ of all cancers in India with an incidence of 1,19,992 cases and 72,616 deaths every year $[16,17]$.

Several national level studies like National Family Health Survey (NFHS), National Sample Survey (NSS) and National Household Survey of Drug and Alcohol Abuse in India (NHSDAA) captures information on tobacco use to assist in forming evidence based effective tobacco control policies. The NFHS survey collected tobacco related data since its second round. The fourth round of NFHS survey (2015-2016) estimated the prevalence of tobacco use amongst adult women $(n=$ 699,686 in 601,509 households) to be $6.8 \%$ (4.4\% in urban and $8.1 \%$ in rural) [18]. Most of these studies lacked comprehensive data on tobacco use among adults. They either focused on local data with urban bias or were a part of other health-based surveys with less focus on tobacco related behavior. In India, Global Adult Tobacco Survey (GATS) was the first nationally representative survey that captured specific tobacco related information. This country wide survey provides a reliable data on tobacco use among adults aged 15 years and above, its correlates including socio-economic, demographic and other key indicators.

Improved education and decreased cultural restrictions have increased the spending capacity of women who have eventually become a soft target group for tobacco industry [6]. Therefore, it is imperative to understand the burden and patterns of SLT use among women so as to formulate gender-based tobacco control policies and programs. The change in trends and burden of SLT use over the years needs to be monitored, to evaluate our existing policies. Hence, the present study was planned to compare two rounds of GATS India data with the following objectives:

1. To estimate and compare the prevalence of smokeless tobacco use among adult females in India using a nationally representative sample from GATS1, 2009-2010 and GATS2, 20162017.

2. To determine and compare the correlates (socioeconomic, demographic) of smokeless tobacco use among adult females in India using data from both rounds of GATS survey.

\section{Methods}

\section{Overview of data}

The Global Adult Tobacco Survey (GATS) is the global standard for monitoring adult tobacco use in a systematic way which tracks key indicators of tobacco control. GATS surveys a nationally representative cross-sectional household based adult samples, aged 15 years and more, using a standard core questionnaire, sample design, and data collection and management procedures for each country. In India, GATS 1 surveyed 29 states and two Union Territories while GATS 2 surveyed 30 states and two Union Territories covering 69,296 \& 74,037 individuals respectively. Stratified multi-stage cluster sampling design was used to identify the specific households for GATS survey. Each state and within each state, rural and urban areas were selected separately for sampling. Primary sampling Unit (PSU) comprised of wards in urban areas which were selected by a three-stage process. During the first stage, a checklist of all wards of towns and cities of each state were obtained which formed the sampling frame. Wards, required for sample, were selected by probability proportional to size (PPS) sampling method. In the next stage, a list of all census enumeration blocks (CEB) were obtained from which one CEB per selected ward was chosen by PPS. In the third stage, required number of residential households were selected from each CEB. In rural areas, households were selected through a two-stage sampling process where villages were PSU, selected through PPS. In the second stage, required number of households were selected from each village.

Amongst the enrolled households, Household Questionnaire was administered to determine the GATS eligibility requirements and to make a list of all eligible residents of the household. Further, one adult was randomly selected from each household to complete the individual questionnaire. The Individual Questionnaire contained questions about individual characteristics; smokeless tobacco use; smoking tobacco and cessation; secondhand smoke; tobaccoeconomics; media; and knowledge, attitudes, and perceptions about tobacco. The detailed methodology for GATS 1 and GATS 2 are published elsewhere [19, 20].

\section{Data collection}

For this study, data was obtained from the website of Centers for Disease Control and Prevention, Atlanta. The data is open access available under the name of Global Tobacco Surveillance System DATA (GTSS Data) which was downloaded after registering with the website. 


\section{Study participants}

Adult females aged 15 years and above from the GATS 1 and GATS 2 formed the participants for this study. Available data of all females from both the rounds of GATS were analyzed for this study.

\section{Sample size}

In GATS 1, 35,529 female participants were surveyed whereas a total of 40,265 females participated in the GATS 2 which formed the sample for this study.

\section{Outcome variable}

The main outcome variable for analysis was smokeless tobacco use. Smokeless tobacco users (SLT Users) and smokeless tobacco non users (SLT Non users) have been classified based on the question "Do you currently use smokeless tobacco on a daily basis, less than daily, or not at all?". All the participants who answered SLT use to be 'daily' or 'less than daily' were classified under SLT users and participants who replied as 'not at all' were listed as SLT Non users.

\section{Independent variables}

In this study, relationship of smokeless tobacco was assessed with the following independent variables: age, residential area (urban/rural), regions of the country (North, Central, East, North-East and West), educational qualification, occupation, wealth index and smoking tobacco $(\mathrm{Yes} / \mathrm{No})$. Age was grouped into four categories 15 to 30 years, 31 to 45 years, 46 to 60 years and more than 60 years. Education was stratified into five categories as those were illiterate (no formal education); incomplete primary school education; completed primary education but not secondary school formed by incorporating "primary school completed" and "less than secondary school completed" from original data; secondary and higher secondary formed by secondary and higher secondary school completed; and graduation and above by merging "college/university completed" and "post graduate degree completed". Further, occupation was classified into six group, the first being government and nongovernment employees formed by merging the government employees and non-government employees as per the original data followed by Daily wage/ casual laborer. Separate data was not available for daily wage/ casual laborer group in the GATS 1 survey hence, daily wage/ casual laborer group was included only for GATS 2 analysis in this study. The further categories under occupation formed were self-employed, student, homemaker and unemployed which was formed by clubbing retired, unemployed but able to work and unemployed but unable to work.

All participants smoking daily or less than daily were grouped as smokers whereas participants who do not smoke at all were clubbed as non-smokers for the analysis. Wealth index was analyzed using Principal Component Analysis based on the possession of household assets through GATS India data. Based on the scores of component analysis, all households were divided into five quintiles. Further, quintile with the highest scores were categorized as rich class, quintile with minimum scores as poor class and the middle three strata as middle class. We took middle class to be more as they represent in the population.

Further, we also analyzed regional variations in the number of women who are willing to quit and attempted to quit SLT. For "willing to quit", we combined all participants who responded that they want to quit within next month or within next 12 months or quit someday, but not within next 12 months and all those who responded that they were not willing to quit as "not willing to quit". For attempted to quit, we categorized "During the past 12 months, have you tried to stop using smokeless tobacco?" with 'yes' as attempted and 'no' as not attempted.

\section{Statistical analysis}

Data were analyzed using STATA version 16.0 (STATA Corp., Texas) and R software (version 4.1.0) for graphs. Mean and Standard Deviation represents the measures of central tendency and dispersion for age. Frequency and proportion (\%) for types of SLT used, sociodemographic characteristics of the participants with their exposure to SLT, are reported. Chi-square test was used to measure the significance between prevalence of GATS-1 and GATS-2. Correlates of SLT exposure were assessed separately using binary logistic regression. The variables which had $p<0.1$ were included in the multivariable logistic regression analysis. We analyzed independent risk factor for all covariates and considered each covariate in regression model. Further, GATS 1 \& 2 data were analyzed separately to calculate and compare Odds Ratio (Strength of Association) for each covariate separately. The association is expressed as Adjusted Odds ratio with 95\% confidence interval (CI). Sampling weights were considered during analysis for both descriptive and regression models. For all weighted proportions, we added $\mathrm{CI}$ as the measure of uncertainty.

\section{Ethical considerations}

This study is based on secondary data obtained from GATS 1and GATS 2 and hence, there is no participant risk. The data used is properly acknowledged and referenced wherever required.

\section{Results}

There were 69,296 and 74,037 total participants $(\geq 15$ years) in GATS-1 and GATS-2 respectively. We 
included 35,529 and 40,265 female participants from both the surveys for analysis (Fig. 1). In the GATS-1, there were $14.91 \%$ daily SLT users and $3.49 \%$ less than daily SLT users, whereas in GATS-2, there were 11.09\% daily SLT users and $1.68 \%$ less than daily SLT users making the prevalence of SLT use to be 18.4 and $12.8 \%$ respectively (Table 1$)$. There was a significant change ( $p$ value $<0.001)$ in SLT use among the women between GATS- 1 and GATS-2. The mean age of female participants in GATS-1 was $36( \pm 16)$ years and that in GATS2 it was $39( \pm 15.3)$ years. The mean initiation age of SLT among females was $22.7( \pm 12.2)$ years and $24.5( \pm 11.7)$ years for GATS-1 and GATS-2 respectively.

We observed oral tobacco products such as gul gudakhu $(5.82 \%)$ to be most commonly used in GATS-1 whereas betel quid with tobacco product $(3.91 \%)$ were more prevalent during GATS-2. The detailed prevalence of different types of SLT products are presented in Table 2. After sub-group analysis, we found that the majority of the women SLT users were $>60$ years of age, belonged to rural areas and were minimally or not at all educated. Participants had varied job profiles and belonged to contrasting economic backgrounds.

Though, the overall prevalence has reduced, a surge was identified in North Eastern population where prevalence in SLT use increased from 29.2 to $35.0 \%$. Among the northern population, SLT users increased by a minimal margin (1.3\% during GATS-1 to $1.73 \%$ during GATS-2). Almost similar prevalence was observed among the self-employed females (23.6\%), Government (Govt.) or Non-Govt. service class (25.1\%) and unemployed (28.93\%) during the first round of GATS. This situation improved with the course of GATS-2, but still a substantial portion of the unemployed cohort (22.56\%) and self-employed (16.43\%) were under the influence of smokeless tobacco. A new sub-group, daily wage/casual laborer, introduced during GATS-2 was the largest contributor (22.7\%) of SLT use. Amongst tobacco smokers, a colossal part $(36.7 \%$ in GATS- 1$)$ were found to be users of smokeless tobacco also (Table 3) representing the dual use of tobacco.

Unadjusted univariate association of each of the covariates with SLT use was calculated as presented in the Table 3. Age is found to be directly associated with SLT use, whereas, educational qualification had an inverse relation. The odds ratio was 27.294 (19.367-38.467) and
24.321 (13.082-45.218) for those who never went to school in GATS-1 and 2 respectively.

Multivariable regression analysis (Table 4) showed the chances of SLT use increased among all age groups during GATS-2 survey with respect to the reference age group (15 to 30 years) than GATS-1. Chances of being a SLT user was highest among the North-Eastern women in both rounds [AOR: $4.567 \quad(3.942-5.292)$ during GATS-1 and 9.149 (7.722-10.839) during GATS-2]. The odds of being a SLT user in rural areas, as compared to urban residents, had reduced from first round [AOR: $1.218(1.103-1.347)]$ to the second round of GATS [1.022 (0.890-1.174)]. Adjusted Odds Ratio increased from GATS-1 to GATS-2 in Central [1.484 (1.287$1.711)$ to $2.244(1.904-2.644)]$ and Western [1.567 (1.349-1.822) to 2.154 (1.789-2.594)] part of India, though only Eastern States of India showed a dip in AOR [3.006 (2.595-3.482) in GATS-1 vs. 2.242 (1.9022.642) in GATS-2].

Educational level evolved as an important contributing factor for SLT use. Women with no formal education had the highest prevalence (28.8 and $22.6 \%$ respectively during 2009-10 and 2016-17) as well as highest chance using SLT in both rounds [AOR: 15.334 (10.783-21.806) during GATS-1 and 11.358 (5.984-21.558) during GATS-2], though both prevalence and AOR, tend to decline in the second round of GATS. A considerable change in AOR was observed across all occupational groups, while daily wage/casual laborer added in GATS 2 had highest prevalence [1.469 (1.206-1.791)]. One of the noticeable findings of our study was, economically well-off women were more addicted to smokeless tobacco (prevalence 24.6 and $20.29 \%$ respectively in GATS-1 \& GATS-2) as compared to the middle and least wealthy class, although the trend of SLT use reduced amongst all the groups. Dual use of tobacco i.e., use of smokeless tobacco with smoking tobacco was comparatively higher but it decreased over time (AOR: 1.182 (0.915-1.526) in GATS-1 and 1.175 (0.861-1.605) in GATS-2) though the changes are not so catchy.

A state level analysis of prevalence of SLT use among women revealed Odisha had highest prevalence of 56.53\% while Himachal Pradesh had lowest $0.14 \%$ during the recent GATS 2 survey (Fig. 2). Punjab, Himachal Pradesh ad Chandigarh continued to have least prevalence of SLT in both the rounds while the prevalence

Table 1 Weighted prevalence of SLT users and non-users in GATS-1 and GATS-2

\begin{tabular}{llll}
\hline GATS $\mathbf{1}(\boldsymbol{n}=\mathbf{3 5 , 5 2 9 )}$ & GATS $\mathbf{2}(\boldsymbol{n}=\mathbf{4 0 , 2 6 5 )}$ & \multicolumn{1}{c}{ - value } \\
\hline SLT Users & SLT Non-Users & SLT Users & SLT Non-Users \\
$\mathrm{n}, \%(\mathrm{Cl})$ & $\mathrm{n}, \%(\mathrm{Cl})$ & $\mathrm{n}, \%(\mathrm{Cl})$ & $\mathrm{n}, \%(\mathrm{Cl})$ \\
6538, & 28,991, & 5140, & 35,125, \\
$18.4(18.0-18.8)$ & $81.6(81.2-82.0)$ & $12.8(12.4-13.1)$ & $87.24(86.9-87.6)$ \\
\hline
\end{tabular}




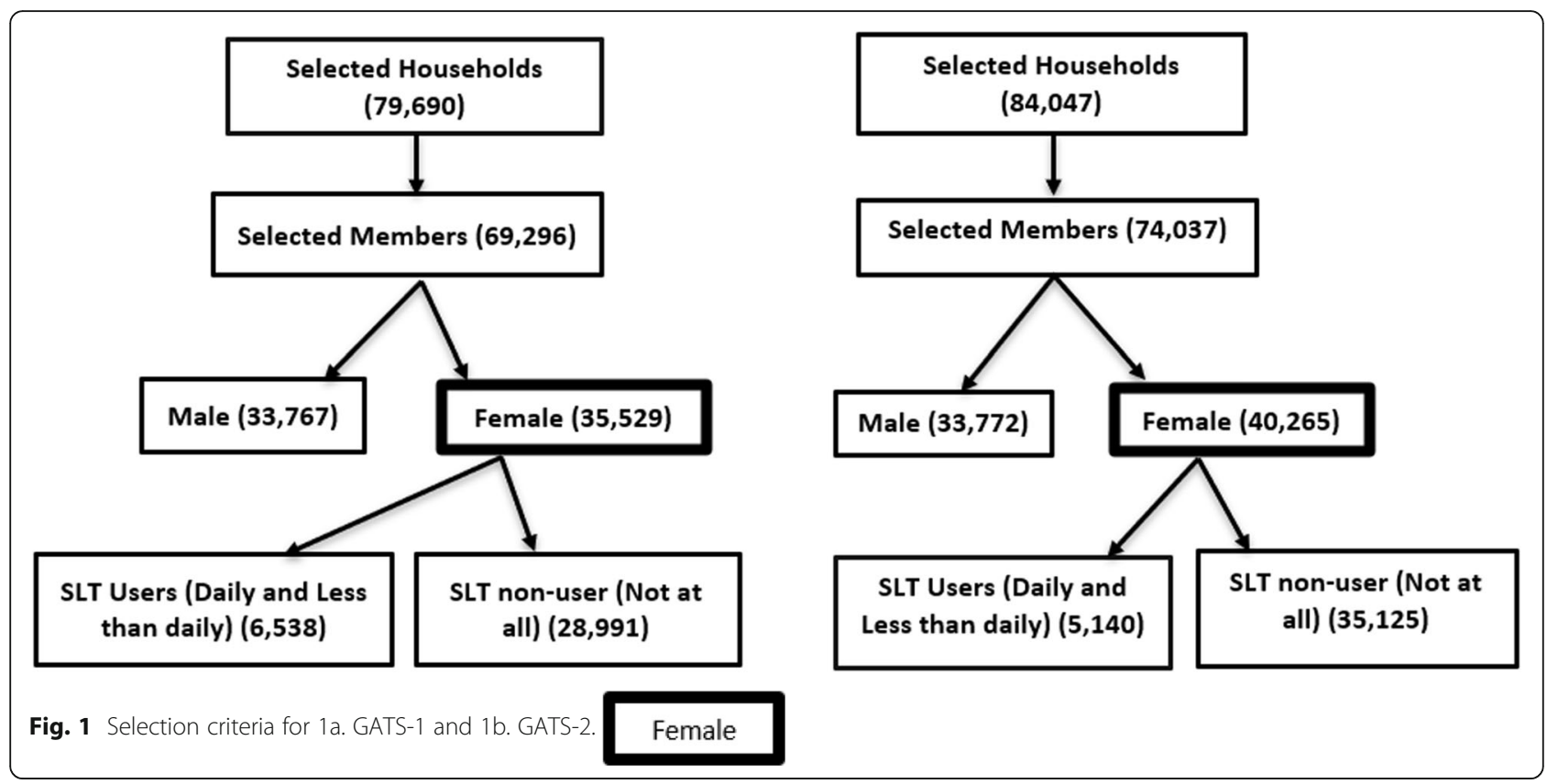

has considerably increased in states like Jharkhand, Odisha and West Bengal during GATS 2. Further, the regional differences (Table 5) across participants willing to quit and attempted to quit revealed a high percentage $33.3 \%$ vs. $34.80 \%$ were willing to quit tobacco whereas $41.48 \%$ vs. $41.7 \%$ of the participants attempted to quit in Central region across both rounds of survey. But, this trend inversed in Southern and Eastern parts of country.

\section{Discussion}

This study provided an overview of smokeless tobacco prevalence and its trend among adult women in India using a nationally representative data from two rounds of GATS Survey. The mean initiation age of SLT among females was $22.7( \pm 12.2)$ years and $24.5( \pm 11.7)$ years for GATS-1 and GATS-2 respectively which is consistent with the findings of a study which reports mean initiation age for any SLT product to be $20.1( \pm 7.5)$ years among women [21]. This also indicated that females tend to initiate SLT use late than their male counterparts whose mean initiation age is reported around 17.24 $( \pm 2.18)$ years [22]. This study reported an overall relative reduction in prevalence of SLT use among adult women in India by about 5\% between GATS 1 and GATS 2 which signifies a large number of people want to quit. Further, prevalence of SLT use among older adults aged $>60$ years appeared to be more than the younger generation which is a positive indicator as fewer

Table 2 Weighted prevalence of different types of Smokeless Tobacco used

\begin{tabular}{|c|c|c|}
\hline \multirow[t]{2}{*}{ Types of SLT } & \multirow{2}{*}{$\begin{array}{l}\text { GATS-1 }(N=35,529) \\
\mathrm{n}, \%(\mathrm{Cl})\end{array}$} & \multirow{2}{*}{$\begin{array}{l}\text { GATS-2 }(N=40,265) \\
n, \%(C I)\end{array}$} \\
\hline & & \\
\hline Betel quid with tobacco product & $\begin{array}{l}1541 \\
4.34(4.13-4.55)\end{array}$ & $\begin{array}{l}1575 \\
3.91(3.72-4.11)\end{array}$ \\
\hline Khaini or tobacco lime mixture & $\begin{array}{l}1602 \\
4.51(4.30-4.73)\end{array}$ & $\begin{array}{l}1492 \\
3.71(3.52-3.89)\end{array}$ \\
\hline Gutkha /tobacco lime, areca nut mixture & $\begin{array}{l}875 \\
2.46(2.30-2.63)\end{array}$ & $\begin{array}{l}888 \\
2.21(2.06-2.35)\end{array}$ \\
\hline Oral tobacco, such as snuff and gul gudakhu & $\begin{array}{l}2069 \\
5.82(5.58-6.07)\end{array}$ & $\begin{array}{l}1560 \\
3.87(3.69-4.07)\end{array}$ \\
\hline Pan masala and betel quid without tobacco & $\begin{array}{l}489 \\
1.38(1.26-1.50)\end{array}$ & $\begin{array}{l}374 \\
0.93(0.84-1.03)\end{array}$ \\
\hline Nasal use of snuff & $\begin{array}{l}374 \\
1.05(0.95-1.16)\end{array}$ & $\begin{array}{l}206 \\
0.51(0.44-0.59)\end{array}$ \\
\hline Others & $\begin{array}{l}963 \\
2.71(2.54-2.88)\end{array}$ & $\begin{array}{l}72 \\
0.18(0.14-0.23)\end{array}$ \\
\hline
\end{tabular}




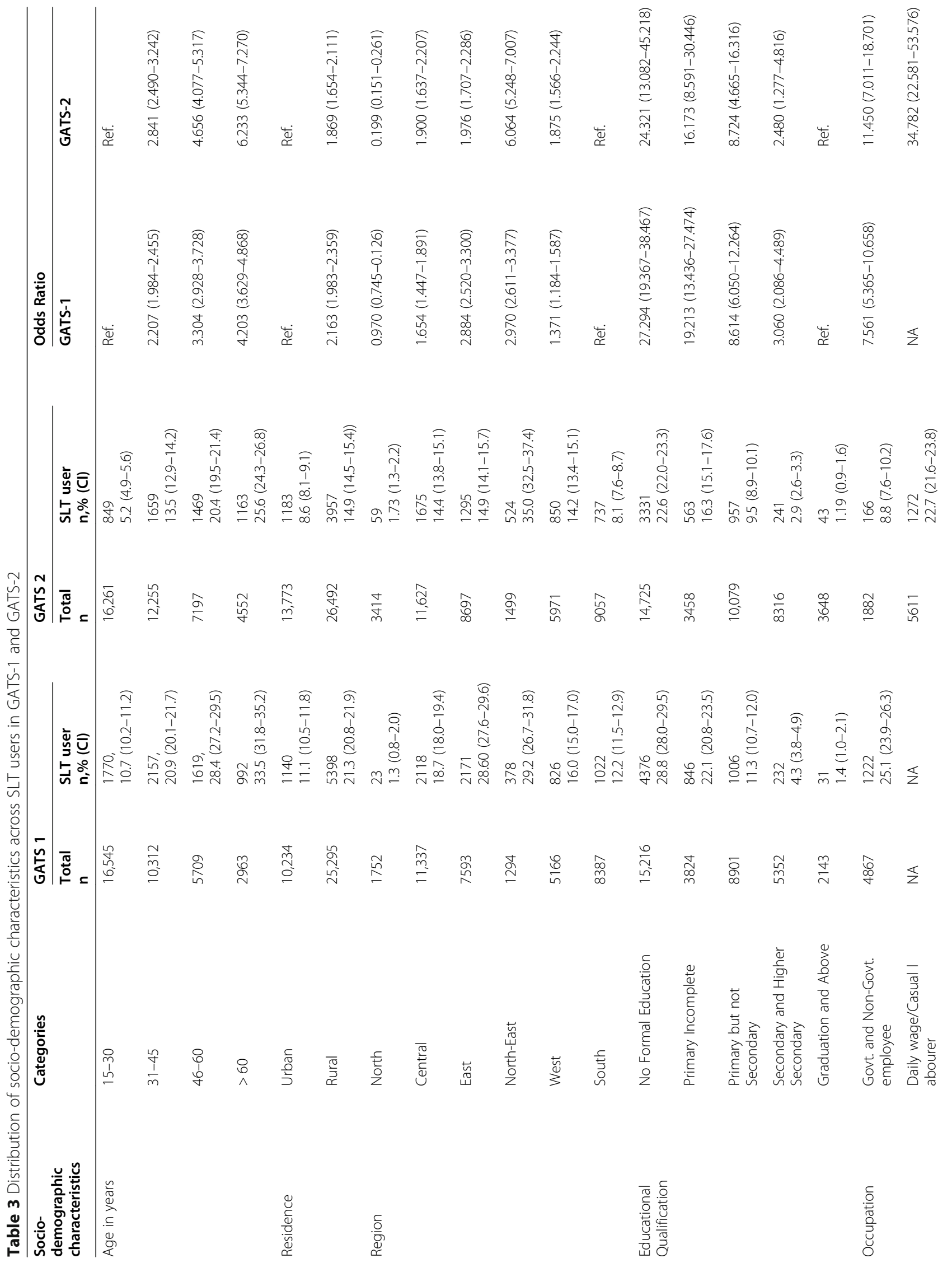




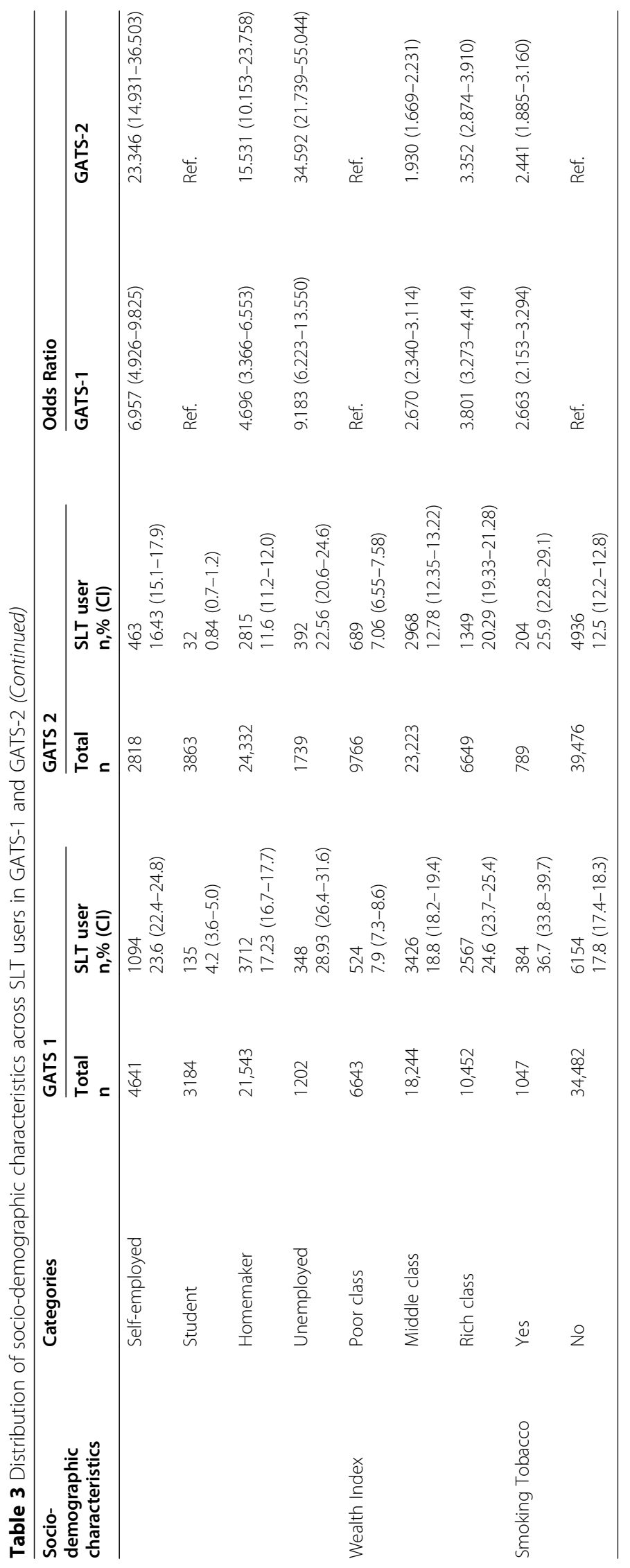


Table 4 Multivariable adjusted models for the association between SLT use and socio-demographic characteristics

\begin{tabular}{|c|c|c|c|}
\hline Socio-demographic characteristics & Categories & AOR $(95 \% \mathrm{Cl})$ & \\
\hline & & GATS 1 & GATS 2 \\
\hline \multirow[t]{4}{*}{ Age } & $15-30$ years & Ref. & Ref. \\
\hline & $31-45$ years & $1.667(1.484-1.874)$ & $1.898(1.638-2.198)$ \\
\hline & $46-60$ years & $2.380(2.077-2.726)$ & $2.941(2.536-3.411)$ \\
\hline & $>60$ years & $3.112(2.615-3.704)$ & $3.691(3.090-4.409)$ \\
\hline \multirow[t]{2}{*}{ Residence } & Urban & Ref. & Ref. \\
\hline & Rural & $1.218(1.103-1.347)$ & $1.022(0.890-1.174)$ \\
\hline \multirow[t]{6}{*}{ Region } & North & $0.105(0.080-0.138)$ & $0.267(0.201-0.355)$ \\
\hline & Central & $1.484(1.287-1.711)$ & $2.244(1.904-2.644)$ \\
\hline & East & $3.006(2.595-3.482)$ & $2.242(1.902-2.642)$ \\
\hline & North-East & $4.567(3.942-5.292)$ & 9.149 (7.722-10.839) \\
\hline & West & $1.567(1.349-1.822)$ & $2.154(1.789-2.594)$ \\
\hline & South & Ref. & Ref. \\
\hline \multirow[t]{5}{*}{ Educational Qualification } & No Formal Education & $15.334(10.783-21.806)$ & $11.358(5.984-21.558)$ \\
\hline & Primary Incomplete & $12.472(8.675-17.931)$ & $8.792(4.593-16.829)$ \\
\hline & Primary but not Secondary & $7.153(5.006-10.219)$ & 6.499 (3.423-12.339) \\
\hline & Secondary and Higher Secondary & $3.273(2.227-4.811)$ & $2.700(1.370-5.321)$ \\
\hline & Graduation and Above & Ref. & Ref. \\
\hline \multirow[t]{6}{*}{ Occupation } & Govt. and Non-Govt. employee & $2.291(1.584-3.314)$ & $1.118(0.801-1.562)$ \\
\hline & Daily wage/Casual labourer & NA & $1.469(1.206-1.791)$ \\
\hline & Self-employed & $1.847(1.277-2.671)$ & $0.180(0.112-0.290)$ \\
\hline & Student & Ref. & Ref. \\
\hline & Homemaker & $1.349(0.947-1.921)$ & $0.724(0.605-0.866)$ \\
\hline & Unemployed & $1.385(0.900-2.130)$ & $0.991(0.750-1.309)$ \\
\hline \multirow[t]{3}{*}{ Wealth Index } & Poor class & Ref. & Ref. \\
\hline & Middle class & $1.508(1.293-1.760)$ & $1.235(1.055-1.447)$ \\
\hline & Rich class & $1.399(1.177-1.663)$ & $1.354(1.129-1.624)$ \\
\hline \multirow[t]{2}{*}{ Smoking Tobacco Use } & Yes & $1.182(0.915-1.526)$ & $1.175(0.861-1.605)$ \\
\hline & No & Ref. & Ref. \\
\hline
\end{tabular}

young people tend to be habitual of tobacco. A substantial part of rural women indulging in SLT use is of great concern. Although, comparing GATS 1 and GATS 2, we assessed percentage reduction in SLT use among rural women was more as compared to urban women indicating their willingness to quit. Hence, more culturally acceptable and linguistically focused programs need to be designed to provide them assistance in quitting.

Tobacco usage varies across different regions of India where North-east India majorly contributes in SLT burden followed by East and Central India. This can be attributed to varied levels of socio-economic development throughout India However, Eastern India has successfully managed to maximally reduce the burden to almost half. This also provides an opportunity to systematically study the factors behind this change and replicate the strategy in other regions too. Education is an important correlate for SLT use in India as this study reported a direct relation between SLT use and level of education. Women with no formal education had highest prevalence of SLT use. This can be attributed to lack of knowledge and various perceptions about the use of SLT in community. Daily wage/casual laborers and unemployed women appear to consume SLT more. Several studies suggest people tend to use tobacco either in free time or when they need to work hard to get a sense of mental relaxation [23]. Here, a noticeable increase in SLT users among the rich strata is observed which strengthens the notion that women being socially and economically more independent have recently become the soft target for tobacco industry. This clearly emphasizes gender based tobacco control policies [24] are required which 


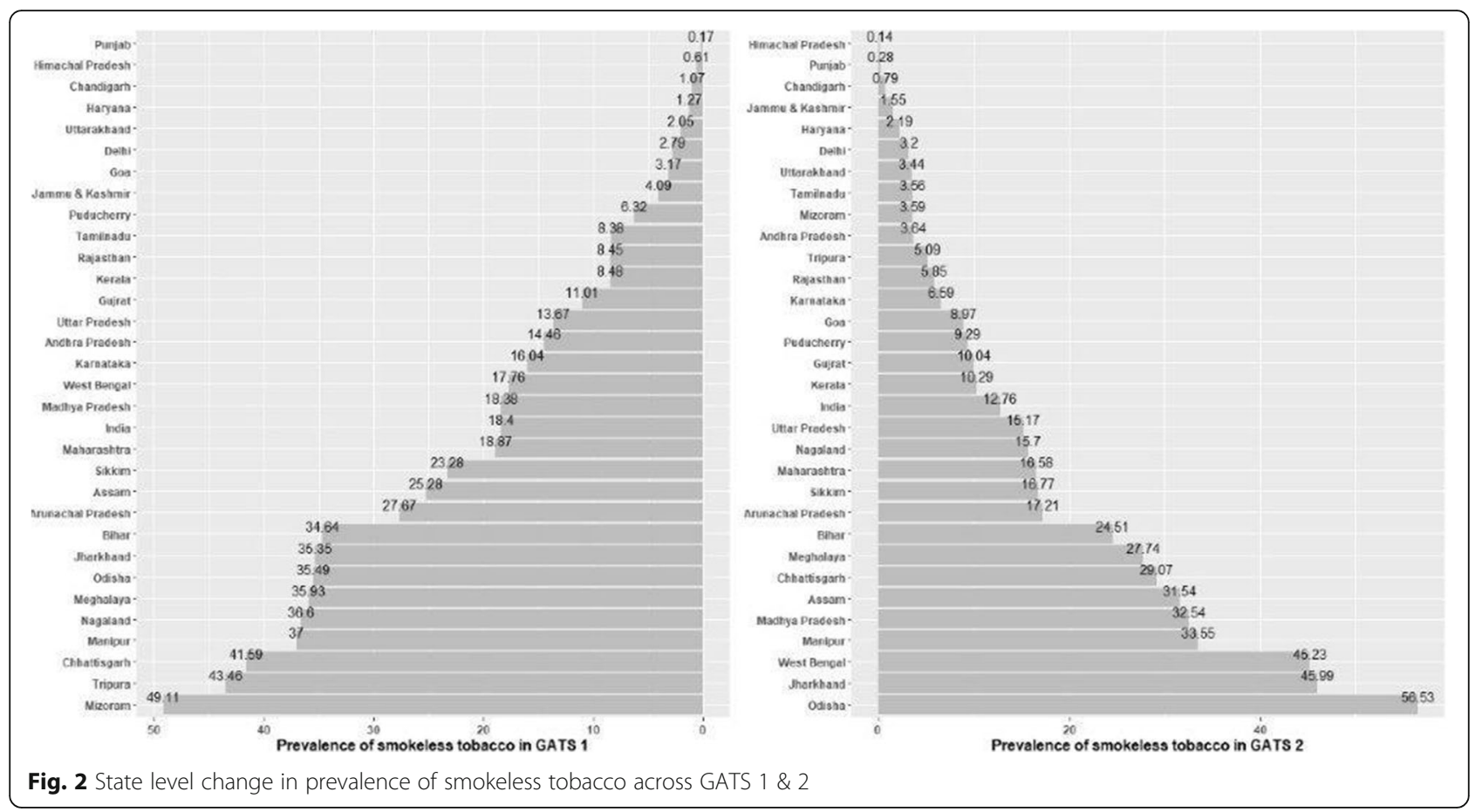

will not only target for health promotion but also empower women to take informed decisions for their health which in turn affects their family's health too.

Dual use of tobacco both as SLT and smoking is widely believed to go hand in hand which is supported by this study too [25]. Here, we observed the prevalence of SLT use $(36.7 \%$ \& $25.9 \%)$ increased concomitantly among the smokers. Dual use of tobacco is potentially one of the highest risk factors for ill effects on general and reproductive health among women. It is worth noting here that $4.91 \%$ vs. $14.03 \%$ were willing to quit tobacco and $4.20 \%$ vs. $8.30 \%$ attempted to quit in North Eastern region across both rounds of survey. This signifies, despite a noticeable surge in prevalence of SLT, the number of people willing to quit and attempted to quit have almost doubled during GTAS 2. This can be treated as an opportunity for policy makers to take lead and help people in quitting. Also, the number of SLT users have considerably increased in states such as Jharkhand, Odisha and West Bengal during GATS 2 which needs a fair attention.

Various tobacco control programmes and policies such as National Tobacco Control Programme (NTCP), 2007-08 and The Cigarettes and Other Tobacco Products (Prohibition of Advertisement and Regulation of Trade and Commerce, Production, Supply and Distribution) Act, 2003 (COTPA) are in implementation in India. India is also a party to the World Health Organization Framework Convention on Tobacco Control (WHO FCTC). NTCP targets to create awareness related to ill effects of tobacco, reduce production and supply of tobacco products and ensure effective implementation of COTPA. It also aims to help people quit tobacco through the WHO FCTC framework. Although, these provisions have helped in reducing the tobacco use but they do not focus on gender dimensions. Hence,

Table 5 Regional differences among willing to quit and attempted to quit tobacco

\begin{tabular}{|c|c|c|c|c|}
\hline \multirow[t]{3}{*}{ Region } & \multicolumn{2}{|l|}{ GATS 1} & \multicolumn{2}{|l|}{ GATS 2} \\
\hline & Willing to quit ( $n=2399$ ) & Attempted to quit $(n=1738)$ & Willing to quit ( $n=2331$ ) & $\begin{array}{l}\text { Attempted to quit } \\
(n=1500)\end{array}$ \\
\hline & $\mathrm{n}, \%(\mathrm{Cl})$ & $\mathrm{n}, \%(\mathrm{Cl})$ & $\mathrm{n}, \%(\mathrm{Cl})$ & $\mathrm{n}, \%(\mathrm{Cl})$ \\
\hline North & $5,0.2(0.07-0.48)$ & $5,0.29(0.09-0.67)$ & $41,1.76(1.27-2.38)$ & $28,1.87(1.24-2.69)$ \\
\hline Central & $799,33.3(31.42-35.23)$ & $721,41.48$ (39.15-43.84) & $811,34.80(32.86-36.77)$ & $626,41.7(39.22-44.28)$ \\
\hline East & $902,37.62(35.66-39.57)$ & $281,16.17(14.47-17.98)$ & 483, 20.74 (19.09-22.42) & $325,21.66(19.61-23.84)$ \\
\hline North-East & $118,4.91(4.09-5.86)$ & $73,4.20(3.30-5.25)$ & $327,14.03(12.64-15.50)$ & $124,8.30(6.92-9.78)$ \\
\hline West & $228,9.5(8.36-1.07)$ & $320,18.41(16.62-20.32)$ & $363,15.58(14.12-17.11)$ & $188,12.52(10.90-14.32)$ \\
\hline South & $347,14.46(13.08-15.94)$ & $338,19.45(17.61-21.39)$ & $306,13.11(11.78-14.57)$ & $209,13.95(12.22-15.79)$ \\
\hline
\end{tabular}


based on this study we recommend following tobacco control measure for this group.

\section{Recommendations}

Gender-based tobacco control policies with bottom-up approach with participation of women should be framed in order to make it culturally and socially acceptable. More tobacco research with greater representation of women is required to generate substantial evidence in this field. Tobacco control programs may aim at women evenly and help them in cessation. Socio-behavioral and cultural factors related to females need to be addressed while framing any regulations for tobacco control. Community based awareness and prevention should aim to reach both males and females equally. Awareness materials should be developed in local language along with more illustrations in order to reach all strata of society. Health professionals should screen and advice for tobacco cessation to all patients attending healthcare centers so that this opportunity is not missed.

\section{Strengths and Limitations}

As per our knowledge, this is the first study to demonstrate trends of smokeless tobacco use among Indian women. We compared the data from GATS-1 \& GATS2 , a nationally representative exclusive adult tobacco survey containing all possible correlates such as age, sex, region, occupation etc. During our study, we were unable to take into account some additional factors like alcoholism, stress, or other habitual and behavioral practices due to data deficit.

\section{Conclusions}

Tobacco control measures have helped in reducing SLT use among women in India over the years but this change needs further pace. Hence, more focused genderbased tobacco control programs and policies should be advocated so that women, a neglected group in tobacco control, do not fall prey in the hands of legalized tobacco industry. More focused gender-based tobacco research to generate concrete evidence is requirement of the time.

\section{Abbreviations \\ SLT: Smokeless Tobacco; NFHS: National Family Health Survey; NSS: National Sample Survey; NHSDAA: National Household Survey of Drug and Alcohol Abuse in India; GATS: Global Adult Tobacco Survey; PSU: Primary Sampling Unit; PPS: Probability Proportional to Size; CEB: Census Enumeration Blocks; GTSS Data: Global Tobacco Surveillance System DATA}

\section{Acknowledgements}

We sincerely thank Dr. Jyoti Ghosal, Senior Research Fellow and Ms. Sushmita Kerketta, MPH Trainee from ICMR-Regional Medical Research Centre, Bhubaneswar for helping us in making histogram and their substantial contribution in revising the manuscript. We also thank Global Tobacco Surveillance System Data for providing GATS India dataset.

\section{Authors' contributions}

AS, SK and SP conceived the study and developed the analytical framework. SG, AS and SK performed the analysis, produced results and drafted manuscript. SP monitored analysis and edited manuscript. SP provided overall guidance and supervised the study. All the authors have read and approved manuscript for publishing.

\section{Funding}

None.

\section{Availability of data and materials}

The datasets generated during and/or analyzed during the current study are available in the Global Tobacco Surveillance System Data (GTSSData) repository, (https://nccd.cdc.gov/GTSSDataSurveyResources/Ancillary/DataReports. aspx? CAID=2).

\section{Declarations}

Ethics approval and consent to participate

This study is based on secondary data obtained from GATS 1 and GATS 2 and hence, there is no participant risk. The data used is properly

acknowledged and referenced wherever required.

\section{Consent for publication}

Not Applicable.Competing interests

The authors declare that they have no competing interests.

Received: 16 May 2021 Accepted: 6 October 2021

Published online: 09 November 2021

References

1. SLT Products - Effective Implementation of Tax \& Tobacco Advertisement, Promotion and Sponsorship (TAPS) measures for Prevention \& Control of Smokeless Tobacco in South East Asia Region (SEAR) [Internet]. [cited 2021 Jan 17]. Available from: http://smokelesstobaccocontrolindia.com/sltproducts/\#!

2. Smokeless tobacco control fact sheet [Internet]. [cited 2021 Jan 17]. Available from: http://smokelesstobaccocontrolindia.com/wp-content/uploa ds/2020/04/Annexure-VI-India-factsheet.pdf

3. Asma S. The GATS atlas: global adult tobacco survey. [cited 2021 Jan 17$].$ Available from: https://stacks.cdc.gov/view/cdc/51993.

4. David A, Esson K, Perucic AM, Fitzpatrick C. Tobacco use: equity and social determinants. Equity. Soc Determinants and Public Health Programmes. 2010;199:218.

5. Schensul JJ, Nair S, Bilgi S, Cromley E, Kadam V, Mello SD, et al. Availability, accessibility and promotion of smokeless tobacco in a low-income area of Mumbai. Tob Control [Internet]. UK: BMJ Publishing Group Ltd; 20131 [cited 2021 Jan 17];22(5):324-330. Available from: https://tobaccocontrol.bmj.com/ content/22/5/324

6. Kakde S, Bhopal RS, Jones CM. A systematic review on the social context of smokeless tobacco use in the South Asian population: Implications for public health [Internet]. 126, Public Health; 2012 [cited 2020 Dec 13]. 635645. Available from: https://pubmed.ncbi.nlm.nih.gov/22809493/.

7. Rogers JM. Tobacco and pregnancy: Overview of exposures and effects [Internet]. 84, Birth Defects Research Part C - Embryo Today: Reviews. USA: John Wiley \& Sons, Ltd; 2008 [cited 2021 Jan 17]. 1-15. Available from: https://onlinelibrary.wiley.com/doi/full/10.1002/bdrc.2011.

8. Mishra GA, Kulkarni SV, Majmudar PV, Gupta SD, Shastri SS. Communitybased tobacco cessation program among women in Mumbai, India. Indian J Cancer [Internet]. Mumbai: Medknow Publications; 20141 [cited 2020 Dec 13]; 51:S54-S59. Available from: https://pubmed.ncbi.nlm.nih.gov/25526250/.

9. World Health Organization. International Agency for Research on Cancer. In: Smokeless tobacco and some tobacco-specific N-Nitrosamines. USA: Smokeless tobacco and some tobacco-specific N-Nitrosamines; 2007.

10. England LJ, Kim SY, Tomar SL, Ray CS, Gupta PC, Eissenberg T, et al. Noncigarette tobacco use among women and adverse pregnancy outcomes. Acta Obstet Gynecol Scand [Internet]. 20101 [cited 2021 Jan 17];89(4):454464. Available from: http://doi.wiley.com/10.3109/00016341003605719.

11. Gupta PC, Sreevidya S. Smokeless tobacco use, birth weight, and gestational age: Population based, prospective cohort study of 1217 women in Mumbai, India. Br Med J [Internet]. USA: BMJ Publishing Group; 200426 
[cited 2021 Jan 17];328(7455):1538-1540. Available from: http://www.bmj. $\mathrm{com} /$

12. Subramoney S, Gupta P. Anemia in pregnant women who use smokeless tobacco. Nicotine Tob Res [Internet]. USA: Oxford Academic; 20081 [cited 2021 Jan 17];10(5):917-920. Available from: https://academic.oup.com/ntr/a rticle-lookup/doi/10.1080/14622200802027206

13. Pednekar MS, Gupta PC, Shukla HC, Hebert JR. Association between tobacco use and body mass index in urban Indian population: Implications for public health in India. BMC Public Health [Internet].; 200616 [cited 2021 Jan 17];6. Available from: https://pubmed.ncbi.nlm.nih.gov/16542418/

14. Muthukrishnan A, Warnakulasuriya S. Oral health consequences of smokeless tobacco use [Internet]. 148, Indian J Med Res, Suppl. Indian Counc Med Res; 2018 [cited 2021 Jan 17]. 35-40. Available from: /pmc/ articles/PMC6172921/?report=abstract.

15. Khan Z, Tönnies J, Müller S. Smokeless Tobacco and Oral Cancer in South Asia: A Systematic Review with Meta-Analysis. J Cancer Epidemiol [Internet]. UK: Hindawi Publishing Corporation; 2014 [cited 2021 Jan 17];2014:1-11. Available from: http://www.hindawi.com/journals/jce/2014/394696/

16. Coelho KR. Challenges of the Oral Cancer Burden in India. J Cancer Epidemiol. UK: Hindawi Publishing Corporation; 2012;2012:17, 17, https://doi. org/10.1155/2012/701932.

17. Oral Cancer - India Against Cancer [Internet]. 2021 . Available from: http://ca ncerindia.org.in/oral-cancer/

18. India-Key Indicators India-Key Indicators INTERNATIONAL INSTITUTE FOR POPULATION SCIENCES [Internet]. 2021. Available from: http://www.rchiips. org/nfhs/http://www.iipsindia.org

19. Krishna Mohan P, Morton J, Hsia J, Andes L, Asma S, Talley B, et al. Methodology of the global adult tobacco survey - 2008-2010. Glob Health Promot [Internet]. USA: SAGE Publications Ltd; 201330 [cited 2020 Dec 29]; 23(2_suppl):3-23. Available from: http://journals.sagepub.com/doi/1 $0.1177 / 1757975913499800$

20. India - Global Adult Tobacco Survey 2016-2017 - Sampling [Internet]. [cited 2020 Dec 29]. Available from: https://nada.searo.who.int/index.php/catalog/ 73/sampling.

21. Begum S, Schensul JJ, Nair S, Donta B. Initiating smokeless tobacco use across reproductive stages. Asian Pac J Cancer Prev. 2015;16(17):7547-54. https://doi.org/10.7314/APJCP.2015.16.17.7547.

22. Nichter M, Nichter M, Van Sickle D. Popular perceptions of tobacco products and patterns of use among male college students in India. Soc Sci Med. 2004;59(2):415-31. https://doi.org/10.1016/j.socscimed.2003.10.032.

23. Thakur JS, Paika R. Determinants of smokeless tobacco use in india [Internet] 148, Indian J Med Res, Suppl. Indian Counc Med Res; 2018 [cited 2020 Dec 13]. 41-5. Available from: https:/pubmed.ncbi.nlm.nih.gov/30264753/

24. Bandyopadhyay A, Irfan M. Gender-based tobacco policies in Bangladesh and India: A prerequisite to counter the smokeless tobacco epidemic. Women Heal [Internet]. Philadelphia: Routledge; 20192 [cited 2020 Dec 13] 59(1):85-100. Available from: https://pubmed.ncbi.nlm.nih.gov/29630490/

25. Singh A, Ladusingh L. Prevalence and Determinants of Tobacco Use in India: Evidence from Recent Global Adult Tobacco Survey Data. Gorlova OY, PLoS ONE [Internet]. USA: Public Library of Science; 20144 [cited 2021 Jan 18];9(12): e1 14073. Available from: https://dx.plos.org/10.1371/journal.pone.0114073

\section{Publisher's Note}

Springer Nature remains neutral with regard to jurisdictional claims in published maps and institutional affiliations.

Ready to submit your research? Choose BMC and benefit from:

- fast, convenient online submission

- thorough peer review by experienced researchers in your field

- rapid publication on acceptance

- support for research data, including large and complex data types

- gold Open Access which fosters wider collaboration and increased citations

- maximum visibility for your research: over $100 \mathrm{M}$ website views per year

At BMC, research is always in progress.

Learn more biomedcentral.com/submissions 